\title{
Producción y programación de series cómicas de TVE en la época franquista: Jaime de Armiñán y las primeras comedias costumbristas
}

Recibido: 04/02/2014

Patricia DIEGO

Universidad de Navarra

pdiegon@unav.es

\author{
María del Mar GRANDío \\ Universidad Católica San Antonio de Murcia \\ mgrandio@ucam.edu
}

Aceptado: 10/03/2014

\begin{abstract}
Resumen
La telecomedia o serie cómica es uno de los géneros más populares de la televisión en España y que tuvo su germen durante la época franquista. En este marco, este artículo tiene como objetivo ofrecer una revisión histórica y destacar las principales características de producción y programáticas de las principales comedias producidas por TVE entre 1956 y 1975, al mismo tiempo que se rescata la memoria de uno de sus mayores exponentes: el dramaturgo Jaime de Armiñán considerado como el primer guionista de televisión. Este autor es pionero en asentar la profesión en España. Artífice de numerosas comedias, entre otras ficciones televisivas, que gozaron del favor del público y que asentaron la comedia de corte costumbrista que después heredarán la mayoría de las producciones domésticas del género. Un formato que es heredero del género teatral y del que se pueden destacar, entre otros, ciertos rasgos comunes como el regionalismo o localismo, personajes estereotipados, deformación de la lengua con objeto humorístico o la tendencia al melodrama y sentimentalismo en las tramas. Estos ingredientes lograron hacer conectar estas comedias con el público, siendo una de las apuestas fuertes de entretenimiento de TVE durante los años mencionados. Algunos de sus títulos más destacados fueron Galería de maridos (1959-1960), Galería de esposas (1960), Mujeres Solas (1960) o Chicas en la ciudad (1961).
\end{abstract}

Palabras clave: telecomedia, comedia, formato, género, programación, franquismo, producción, teatro, guión, Jaime de Armiñán.

\section{Production and programming of television comedies in Franco's regime: Jaime de Armiñán and the first traditional comedies}

\begin{abstract}
Comic series or TV comedies are one of the most popular genres in Spain had its origin during Franco's regime. In this context, this article aims to provide a historical review and highlight the main features of production and programming of the major comedies produced and programmed by TVE between 1956 and 1975, while the memory of one of its greatest exponents is rescued: Jaime de Armiñán, who is considered one the first TV scriptwriters in Spain. This creator is a pioneer in setting this TV profession in Spain. Author of numerous plays, including television fiction, many of his comedies shaped the basis of the current TV sitcom in Spain. Having their main goal to entertain the viewers while educating them, the TV comedy of this time presented recognizable or stereotypical characters; the twisting of language to comic ends: plays on words, double entendres, etc.; and plots and stories tending towards melodrama and sentimentalism. Some of the most remarkabl titles by Armiñán were Galería de maridos (1959-1960), Galería de esposas (1960), Mujeres Solas (1960) o Chicas en la ciudad (1961).
\end{abstract}

Keywords: TV comedy, format, genre, programming, Franco, production, theater, script, Jaime de Armiñán.

Referencia normalizada: DIEGO, Patricia y GRANDÍO, María del Mar (2014): "Producción y programación de series cómicas de TVE en la época franquista: Jaime de Armiñán y las primeras comedias 
costumbristas". Estudios sobre el Mensaje Periodístico, Vbl. 20, Núm. especial, pp. 105-120. Madrid, Servicio de Publicaciones de la Universidad Complutense.

Sumario: 1. Origen y características generales de la comedia televisiva en España en la época franquista. 2. Hipótesis, objetivos y metodología. 3. Resultados; 3.1. Estándares de producción de las comedias de TVE; 3.2. Jaime de Armiñán y las primeras comedias de los años sesenta; 3.2.1. Programación y producción en las comedias de Jaime Armiñán. 4. Discusión. 5. Referencias.

\section{Origen y características generales de la comedia televisiva en España en la época franquista}

La comedia en España, lejos de ser considerada un género menor tanto para público como académicos, ha gozado de gran popularidad entre la sociedad tanto en la televisión como en el cine, siendo uno de los géneros que mejor representan la función de entretenimiento audiovisual y que, en la actualidad, está despertando también interés entre los investigadores de nuestro país por la fuerte conexión que tiene con la historia reciente y con la satisfacción televisiva de la audiencia contemporánea $(\mathrm{Ca}-$ rrasco, 2011; Grandío y Diego, 2009).

Si nos centramos en la televisión, la comedia televisiva española surge en el seno de la época hegemónica de TVE, denominada en el ámbito académico como "paleotelevisión", una época en la que Televisión Española se presentaba como única oferta televisiva en España y cuyos contenidos se presentaban como una reafirmación de los valores propios del Régimen Franquista (Cortés, 1999: 17-22). Con esta particularidad, se configuró un tipo de comedia televisiva en España que presenta una peculiar mezcla de géneros. En primer lugar, una gran influencia del teatro ya que los primeros autores de comedias en televisión venían en su mayoría del mundo teatral (Palacio, 2001: 145-148). El segundo ingrediente es el de la comedia cinematográfica española de los años sesenta y setenta (entre otras producciones cinematográficas, se encuentran las llamadas comedias "a la española" o "españoladas" realizadas por directores como Mariano Ozores, Tito Fernández, Pedro Lazaga o Fernando Palacios). La mezcla de estos dos modos de trabajar la destaca García de Castro:

"Tanto los [...] teleteatros [...] como telenovelas se convertirán durante los primeros años de la televisión en España en la escuela de la denominada "tercera vía", intermedia entre el teatro y el cine. Escuela autodidacta de profesionales procedentes fundamentalmente del teatro, y posteriormente de la Escuela de Cine, que de forma empírica fueron descubriendo con la práctica y el uso de las telecámaras un nuevo lenguaje narrativo genuino de la televisión" (García de Castro, 2010: 25).

Por último, también se percibe una cierta influencia de la Situation Comedy americana ya que en los años 60 llegaron a TVE exitosas sitcoms como I love Lucy o Embrujadas y que influyeron progresivamente en la producción de comedia televisiva en nuestro país (Diego, 2010: 48-49).

De esta manera, durante esta primera época de emisiones cómicas a través de la televisión en España se fue configurando un género con características propias, que gozó de gran éxito entre el público, y que desde el punto de vista de la producción y creación se presenta además como germen de la comedia televisiva actual. 
El género de la comedia televisiva española ha sido tradicionalmente denominado en España como telecomedia. Aunque, al igual que la evolución del género (Comedy) en su país de origen, Estados Unidos, se ha materializado en diferentes formatos como el sketch show, la comedia de stand-up o los dibujos animados para adultos (adult animation) (Creeber, 2001: 13-113). Probablemente sea la sitcom ${ }^{1}$ el formato con mayor tradición, apoyo popular y peso específico dentro de la industria americana de televisión aunque no tanto en la industria de ficción nacional española, que presenta esa mezcla de géneros antes diferenciados: la sitcom americana, el teatro encarnado en el género del sainete; y la comedia cinematográfica de los años 60, 70 y 80 (Grandío y Diego, 2009: 88). De ahí que algunas características tanto del sainete ${ }^{2}$ como de la sitcom, presentes también en las parrillas de TVE, podemos encontrarlas en las primeras telecomedias españolas costumbristas de esta época, aunque con más predominio de la tradición teatral que por bagaje profesional tenían los primeros creadores. Se describen a continuación:

1. Siguiendo la característica principal de la comedia clásica televisiva, se pretende ofrecer una visión amable y edulcorada de la realidad con el fin de entretener al espectador.

2. Se observa una representación principalmente de la clase popular como protagonista de las historias narradas. De ahí la fuerte conexión con el público generalista.

3. Se utilizan regionalismos o localismos relacionados con lo folclórico (andalucismo, madrileñismo...) tanto en los gags visuales como, sobre todo, en los diálogos. Gran importancia de los gags sonoros a través de la deformación del lenguaje con fines humorísticos.

4. Los personajes protagonistas de estas series responden a tipos recurrentes, a estereotipos fácilmente reconocibles por la audiencia.

1 Si se quiere profundizar en detalle sobre el género anglosajón de la sitcom se pueden consultar: Berciano, Rosa (1999), La comedia enlatada. De Lucille Ball a Los Simpson, Barcelona: Gedisa y Villagrasa, J.M. (2010), ¡Atrápalos como puedas!. La competencia televisiva: programación y géneros, Valencia: Tirant lo blanch. Algunas de las carácterísticas del género americano están recogidas recientemente por Puebla, Belén (2012), "La comedia de situación en España. Características y evolución del formato" en A.A.V.V., Ficcionando. Series de televisión a la española, pp. 16-18, Madrid: Fragua.

2 Juan Antonio Ríos Carratalá señala como propias del género sainetesco algunas características que pueden aplicarse a muchas telecomedias españolas: Regionalismos o localismos, personajes que responden a tipos recurrentes o estereotipados, usar el lenguaje con objeto humorístico (juegos de palabras, dobles significados, etc.), tendencia al melodrama y sentimentalismo en tramas y argumentos, numerosas escenas que no hacen avanzar la acción dramática sino que están basadas en el diálogo, los finales de estas obras suelen ser felices, tendencia a la moraleja final o al adoctrinamiento, utilización de chistes y retruécanos, ambiente costumbrista para dar una imagen más global de la realidad, representación de la clase popular, idealización de los ambientes sociales sin resaltar los aspectos negativos de la realidad, reflejo amable e ingenuo de la realidad ya que la finalidad del género es divertir al espectador (Ríos, 1997: 21-22). 
5. La utilización de chistes es característico de ambientes costumbristas donde se ofrece una representación de la clase popular.

6. Las escenas se basan mucho en los diálogos y no hacen avanzar la acción dramática.

7. Se da una abundancia de finales felices en estas producciones, más propios de otros géneros como la telenovela. En este sentido, hay una clara tendencia al melodrama en estas telecomedias, algo que derivará en otro género propio de la programación española actual (originario de los noventa) como es el dramedia, y a una representación conservadora de los valores propios de la época, sobre todo los relacionados con la vida familiar, protagonista de dichas historias.

8. Desde el punto de vista de la producción, se presenta un escenario tradicional para sugerir realismo en la representación. Las escenas se graban en interiores, con clara influencia de la representación teatral, algo que comparte con la sitcom americana.

A continuación haremos un breve repaso por décadas de algunos de los títulos más representativos del género.

En los años cincuenta, la primera serie producida por TVE fue la telecomedia titulada Los Tele-Rodríguez (1957) protagonizada por María Fernanda D’Ocón, dirigida por Mario Antolín y con guiones de Arturo Ruíz Castillo (Baget, 1993: 44; Diego, 2010: 37). En tono de comedia familiar, reflejaba la vida cotidiana de los Rodríguez que adquieren por primera vez una televisión y su vida cambia con la llegada del nuevo electrodoméstico. Compuesta por capítulos de 25 minutos permanece en emisión desde 1957 hasta agosto de 1958. Los autores la consideran la primera serie de televisión en España ya que se estrenó sólo cuatro meses después del inicio de las emisiones regulares. Francisco José Montes señala la aparición de Los Tele-Rodríguez como el origen del género cómico:

"La programación del primer trimestre fue muy semejante a la de finales de 1957 [...] En los programas dramáticos se dio un gran avance; adaptaciones teatrales dirigidas por Juan Guerrero Zamora y Domingo Almendros; serie policíaca bajo el título general de $E l$ enigma y otro específico que comenzaba con El caso de..., realizado por Alfonso Lapeña; Los Tele-Rodríguez, protagonizada por María Fernanda D’Ocón y dirigida por Mario Antolín; otros guiones expresamente escritos para televisión, antesalas de las telecomedias que se asentarían durante largos años en TVE” (Montes, 2006: 651).

Una segunda comedia que también ayudó a asentar el género fue ;Qué felices somos! escrita por José Mallorquí y protagonizada por Antonio Ozores, Elisa Montés y Tota Albá. En tono de comedia se presentaban los enredos que provocaban una sobrina alocada y su tía, de carácter gruñón, que tenía que resolverlos siempre. Esta producción fue impulsada por Mariano Ozores que en 1958 es nombrado Jefe de Programas en sustitución de José Luis Colina (Baget, 1993: 36).

El género de comedia sufrirá un impulso gracias al papel de destacados autores como Jaime Armiñán, guionista que proviene del mundo del teatro y que analizaremos con más detalle, y que se consagró en televisión con series cómicas como Galería de Maridos 1959 y Galería de Esposas de 1960 con Adolfo Marsillach y Amparo Baró de pareja protagonista; y Mujeres Solas 1960 y Chicas en la Ciudad en 1961, estas úl- 
timas con Amparo Baró, Elena María Tejeiro, Maite Blasco y Alicia Hermida (Galán, 2012: 103-110). Como se puede observar, en estas primeras comedias televisivas se fue afianzando una manera de producir comedia en España basada en un Star System español, es decir, en articular las narrativas televisivas en torno a jóvenes promesas que rápidamente se consagraron en el ámbito artístico español de la época. Todas estas series tuvieron una duración de 25-30 minutos por episodio, duración que se ajusta perfectamente al formato de sitcom americana (Berciano, 1999: 35-48).

A mediados de la década de los sesenta el género de la comedia se consagra en la producción nacional de la mano de dos autores también escritores y dramaturgos como fueron Álvaro de Laiglesia, discípulo de Miguel Mihura, y especialmente Victor Ruiz Iriarte figura clave que también contribuye de manera decisiva en el éxito de este formato para el público (Díaz, 2010: 7). En 1966 estrenaron las comedias El tercer rombo (de Laiglesia) y La pequeña comedia (Ruiz Iriarte) siendo el inicio de su larga colaboración como guionistas con TVE. Así define García de Castro el estilo de humor que se destilaban estas telecomedias:

"Estas fueron dos de estas series cómicas o tragicómicas de talante bastante conservador. A pesar de la novedad de los autores, en estas series sigue estando muy presente la tragedia o la pequeña tragedia al uso, así como el humor y la intrascendencia. Unos guiones convencionales, recargados de diálogos son las características que surge de ellos" (García de Castro, 2002: 37).

El escritor y también guionista Fernando Vizcaino Casas hacía las siguientes declaraciones a la muerte de Álvaro de Laiglesia en 1981 intentando destacar lo más interesante de lo aportado por el dramaturgo al humor español ya que su mayor mérito era haber renovado el humor español:

"Su humor tenía una posición intermedia entre el clásico de 1927, representado por Miguel Mihura, y el humor actual. Alvaro fue una cabeza de puente entre dos formas de humorismo. Como director de La Codorniz fue un poco la nodriza de las generaciones de humoristas españoles de nuestro tiempo" (El País, 2981).

La telecomedia de la década de 1970 está también dominada por Armiñán, (Carrasco, 2011: 77) quien realizará Las doce caras de Eva (1971), siguiendo la misma fórmula que Las doce caras de Juan; Tres eran tres (1972), relato de los choques y desavenencias de tres hermanas huérfanas criadas en hogares diferentes que, por circunstancias, vuelven a reunirse; y Suspiros de España (1974). García de Castro resalta que "Armiñán fue a la telecomedia lo que Juan Gerrero Zamora a los programas dramáticos mencionados" (García de Castro, 2010: 30).

No todo fue producción nacional en durante la década de los 60 y 70. Desde 1959 se pudieron ver habitualmente series de médicos (Cannon), abogados (Señor Fiscal), policíacas (Perry Mason) o aventuras (El Santo). También las comedias televisivas extranjeras, sobre todo británicas y americanas, han estado en la Televisión Española desde los inicios de las retransmisiones televisivas. Desde finales de los 50 se estrenaron en España famosas sitcoms como Te quiero Lucy (I Love Lucy), Embrujadas (Bewitched) o Un hombre en casa (Man about the house) (Baget Herms, 1993: 121196). El lenguaje de estas series va influyendo en el público y en creadores de series 
(guionistas, directores y productores) que comienzan a emular estas producciones ajenas. En el terreno de la comedia también se intento seguir el planteamiento de producción americano aunque sin mucho éxito:

"Con vocación de comedia doméstica se realizaría La familia Colón, que aspiraba a tener los aires del telefilme familiar americano, pero que, según recuerdan los cronistas, no llegó a convencer a nadie" (García de Castro, 2010: 40).

Este intento de producir series a la "americana" no tuvo el resultado esperado por TVE. Por un lado, la falta de medios técnicos y de presupuesto para imitar bien ciertos géneros como el policíaco con complicadas escenas de acción, suspense o efectos especiales, etc. Y, en segundo término, desde el punto de vista de la realización tampoco fructiferó el uso de cámaras de cine como telecámaras, método habitual en el caso anglosajón (García de Castro, 2010: 41).

\section{Hipótesis, objetivos y metodología}

Este trabajo se basa en dos hipótesis de partida: 1) los estándares de producción y la programación en la parrilla televisiva representan dos variables centrales en el proceso de creación de una comedia televisiva, y a las cuales se supeditarán otras variables creativas como la escritura de guión, el vestuario, casting, etc, 2) la producción y la programación de las primeras comedias televisivas, cuyo máximo exponente es Jaime de Armiñán, conforman la esencia de la telecomedia en España actual. Es, por tanto, pertinente desde el punto de vista académico, visibilizar y revalorizar estas primeras comedias desde esta doble vertiente, un área hasta el momento poco investigada y que permitirá indagar en la especificidad de la telecomedia española y sus orígenes, así como ofrecer interesantes reflexiones sobre la labor de creación de comedias televisivas en España en la actualidad.

De ahí que, formuladas estas hipótesis, el objetivo principal de este artículo sea analizar las características principales de las primeras comedias costumbristas españolas desde la perspectiva de producción y programación, dos claves que han marcado la naturaleza de la industria televisiva en nuestro país. La metodología de análisis utilizada para ello es doble: en la parte de producción, se ha acudido a la fuente directa de las entrevistas realizadas al propio Jaime Armiñán y recogidas por Emetrio Diez (2005) así como de otros autores especializados en esa parte de la historia y en la evolución de la producción de series nacionales; en referencia a la programación, se ha consultado directamente la revista de televisión más veterana de nuestro país: Telediario. En concreto, se ha realizado un estudio pormenorizado de los tres primeros años de emisión de TVE (1959-1961) para estudiar la programación de las primeras comedias de Jaime de Armiñán.

La originalidad de este artículo radica en poner de relieve y combinar estas dos variables de producción y programación de las primeras comedias televisivas españolas para ahondar en las características propias de uno de los formatos con más tradición en España. 


\section{Resultados}

\subsection{Estándares de producción de las comedias de TVE}

Una vez realizada una panorámica general de la telecomedia en las décadas de los 50, 60 y 70, pasamos en este epígrafe a estudiar el proceso de producción de estas series. Como hemos visto hasta el momento, TVE cultivó desde época muy temprana un género de ficción netamente televisivo, es decir, productos escritos y producidos por y para la pequeña pantalla, aunque con claras influencias del cine y del teatro. Sin embargo, a diferencia del teatro televisado propio de los primeros años de emisión televisiva en España, estas producciones basan su original planteamiento en la serialidad de mayor duración y en una mejor adecuación a las posibilidades estilísticas del medio.

Durante la etapa monopolista de TVE, los programas televisivos eran producidos por la propia cadena, bien íntegramente o bien en asociación con productoras externas, provenientes en su mayoría del sector cinematográfico. Durante las primeras décadas, la cadena pública asumió el papel de pionera en la estandarización de los primeros géneros televisivos.

Las series televisivas producidas por TVE desde 1956 hasta 1990, época hegemónica de Televisión Española, son cuantiosas y se englobarían tanto las de tinte más dramático como las comedias. Si atendemos a uno de los estándares de producción como es el soporte de grabación con el que están realizadas podemos clasificarlas en dos: series videográficas y cinematográficas.

Las series realizadas en vídeo sufrieron una evolución desde las primeras emitidas en directo hasta que descubrieron las posibilidades que ofrecía el montaje posterior gracias al uso del magnetoscopio. En general, las series realizadas en soporte videográfico tenían un plan de grabación y unos presupuestos más estandarizados que las series cinematográficas (Diego, 2010: 34). La siguiente tabla recoge la comparación entre los principales estándares de producción de los dos tipos de series mencionadas:

Tabla 1. Estándares de producción de series en vídeo y en cine en TVE (1956-1990)

\begin{tabular}{|l|l|l|}
\hline Estándares de producción & Series videográficas & Series cinematográficas \\
\hline Soporte & Cámara de vídeo & Cámara de cine \\
\hline Duración & De 15 a 30 minutos por capítulo & De 50 a 60 minutos \\
\hline $\begin{array}{l}\text { Tiempo de grabación o } \\
\text { rodaje }\end{array}$ & 5 días por capítulo & Extensos planes de rodaje \\
\hline Número de cámaras & 3 ó 4 cámaras (sistema multicámara) & 1 ó 2 cámaras \\
\hline Localizaciones & La mayoría en plató. Escasos exteriores & $\begin{array}{l}\text { Plató y localizaciones naturales (exteriores } \\
\text { o interiores) }\end{array}$ \\
\hline Decorados & Escasos decorados & Numerosos decorados \\
\hline Tiempo de emisión & En directo hasta los años 60 & En diferido \\
\hline Temática & $\begin{array}{l}\text { Predominio de historias dramáticas } \\
\text { sobre cómicas }\end{array}$ & Historia dramáticas, aventura, intriga \\
\hline Modalidad de producción & Producción interna & $\begin{array}{l}\text { Producciones independientes (asociadas o } \\
\text { financiadas) }\end{array}$ \\
\hline Presupuestos & $150-300$ millones de pts. (1 ó 2 m. de $€$ ) & Muy elevados (viajes, alojamiento, etc...) \\
\hline
\end{tabular}

Fuente: Diego, Patricia (2010): La ficción en la pequeña pantalla.

Cincuenta años de series en España. Eunsa, Pamplona p. 34. 
La ausencia de competencia televisiva durante la época franquista provocó que las series de TVE fueran series de "corto recorrido". Es decir, producciones que no pretendían continuar y extenderse más allá de una temporada o de los 13 primeros episodios. No existía la obsesión por las audiencias propia de la neotelevisión. Para tomar la decisión de producir una serie bastaba con que la idea gustara a los directivos de la cadena y estuviera avalada por un profesional (productor, director, guionista o actor) de renombre. Se buscaba que las producciones aportaran prestigio a la cadena (Diego, 2010: 35)

\subsection{Jaime de Armiñán y las primeras comedias de los años sesenta}

Como ya hemos mencionado anteriormente es posiblemente el primer guionista de televisión. Todos los profesionales le consideran el "padre" y precursor de la profesión. Es una de las primeras personas que comenzó a escribir guiones originales para TVE y el primero que los publicó. En su caso el prestigio del guionista sobresalió por encima del realizador o actor ya que también coqueteó con estas dos profesiones. Su nombre era un reclamo para el público (Díez, 2005: 7). Recientemente, ha recibido premios tan importantes como el Goya de Honor 2014 a toda su trayectoria (El País, 2013).

Armiñán comienza su trayectoria profesional en el teatro en 1954 con la comedia Eva sin manzana. Ruiz Ramón califica el estilo de teatro que escribe Armiñán como de teatro "público". Es un teatro de consumo muy diferente del teatro social y de compromiso característico de autores como Buero Vallejo o Alfonso Sastre. Otros exponentes de este teatro más comercial son también José María Pemán, Victor Ruiz Iriarte, Alfonso Paso o Carlos Llopis entre otros. Ruiz Ramón (1986, pp. 295-300) destaca las características estándar de estas obras y Emeterio Diéz (2005: 8) las sintetiza de manera clara en los siguientes aspectos:

- Obras de perfecta técnica teatral

- Temáticas centradas en el tema del amor burgués (matrimonio, infidelidad, los desengaños..)

- Tendencia clara a la comedia

- Protagonizadas por personajes de clase pudiente o noble

- Situadas en ambientes de clases sociales elevadas (aristocráticos o internacionales)

- Enmarcadas en ambientes o épocas históricas que denotan cierta nostalgia del pasado.

El desembarco de este autor en la televisión, con unos inicios duros, estuvo motivado principalmente por razones económicas que hacen que permanezca décadas trabajando para la pequeña pantalla. A pesar de ello su producción teatral no cesa y durante años compatibiliza la escritura en los dos medios. A través del director José Luis García Berlanga su mujer, la actriz Elena Santoja, conoce a Luis Colina (Director de Programas de TVE) y le encarga presentar un magazine de corte femenino, Entre nosotras, en el que Armiñán escribía los guiones. La producción no goza de éxito entre el escaso público televisivo de entonces. En 1958 sólo existían unos pocos privilegiados en Madrid que tuvieran televisor en casa. A pesar de este primer fracaso 
José Luis Colina le ofrece la oportunidad de escribir los guiones de una serie infantil que se iba a llamar Érase una vez (1958-1959) pero tampoco alcanza el éxito ya que el autor intentó alejarse, quizá demasiado para la época, del tópico de los personajes infantiles. El mismo Armiñán narra su pretensión con esta producción:

"Se trataba de juicios a personajes de cuentos: a la madrastra de Blancanieves, al ogro, a la bruja [...] la gracia estaba en que los malos eran buenos [...] la madrastra era encantadora, Blancanieves, una tía cursi, Caperucita Roja [...] una coqueta niña espantosa, y el bueno era el lobo. Por eso no se lo tragaron los niños. Les pedimos a los críos que enviaran cartas declarando culpable o inocente al enjuiciado y escribían: “ ¡La madrastra era: culpable!” "EEl lobo era: culpable!” Total, que hubo que cambiar [...]. Eso los niños del año 36 lo admitían y luego los del 60 no" (Díez, 2005: 23).

TVE decide encargarle una segunda serie titulada Cuentos para mayores, programada cada quince días, la noche de los viernes y sus capítulos de 30 minutos a veces de tono humorístico o fantástico tampoco consiguen calar entre el público quizá, a opinión del autor, por demasiados pretenciosos e intelectuales (Diez, 2005: 24).

Es en la temporada 1959- 1960 cuando su carrera da un giro al ofrecer a la cadena una serie mucho más ligera y con un tono de comedia más marcado que desde el primer capítulo se convierte en un éxito. A Galería de maridos se le puede considerar la primera telecomedia nacional. Estrenada el domingo 11 de octubre de 1959 y en programación de sobremesa, el concepto de esta serie antológica ${ }^{3}$ era retratar el clave de humor el gran abanico de matrimonios posibles. El formato estaba compuesto por episodios de 15 minutos y estaba producido con poco presupuesto y escasos medios. Sólo destacaban los dos actores protagonistas que daban vida a los diferentes matrimonios y un único decorado. Adolfo Marsillach daba vida a todos los tipos de maridos. Unos personajes estereotipados típicos del género comedia (el violento, el fúnebre, el hincha, el jugador, etc.). La actriz Amparo Baró daba vida a Paula, la sufrida mujer que los aguantaba. Se programó los domingos en horario de sobremesa. TVE pagaba a Armiñán por cada guión de esta serie 350 pesetas (Díez, 2005: 24).

Como resultado del gran éxito de la comedia anterior se produce la secuela Galería de esposas (1960) con Antonio Ferrandis, Margot Cottens y Alicia Hermida. En 1960 se produce un spin off, posiblemente el primero de la televisión en España, cuando el personaje de Paula (Amparo Baró) de Galería de maridos, que ya había finalizado, pasa a protagonizar la comedia Mientras ellos trabajan (1960) que narraba, esta vez de modo episódico ${ }^{4}$, las peripecias vividas por Paula en sus días de veraneo

3 Serie antológica se le considera a las que están formadas por episodios independientes. La acción se inicia, se desarrolla y se acaba en cada capítulo. Los personajes son diferentes e incluso a veces el género también cambia. Estas series mantiene una unidad temática en todas las entregas. Algunas series de Armián que siguen este formato de guión fueron Galería de esposas, Álvaro y su mundo, Confidencias o Las doce caras de Juan. (Díez, 2005: 22).

4 Las series episódicas son las que mantiene unos personajes fijos y en cada episodio se narra una trama que comienza, se desarrolla y finaliza con el capítulo. Algunas series de Armiñán que sigue este formato de guión son: Una pareja cualquiera, Mujeres solas o Chicas de la ciudad (Díez, 2005: 22). 
(Díez, 2005: 25). Aprovechando este misma temática pero dándole un giro de tuerca escribe la comedia Cuando ellas veranean (1960) donde el protagonista es un "Rodríguez". La historia se centra en un hombre que se queda sólo en la ciudad mientras su mujer se va de vacaciones.

Otras comedias exitosas y relevantes fueron también Mujeres solas (1961), Galería (1962), Chicas en la ciudad (1962) entre otras. El trabajo creativo de este autor es muy prolíficos durante estos años y destila un sello único de autor en sus comedias:

"Jaime de Armiñán ha encontrado su medio y su estilo. Su nueva dramaturgia se basa en el retrato de personajes muy cercanos y familiares al público, así como en la descripción de situaciones cotidianas. Emplea, además, un tono de ternura y humor; y los temas, mediatizados por la censura se plantean a media voz, mediante un tratamiento de la acción que busca más sugerir que mostrar. Se trata de huir del gran dramatismo, de los sucesos extraordinarios o históricos, de los temas transcendentes. Prefiere los problemas internos, casi domésticos, de las personas, pero, como digo, con guiones alegres y una puesta en escena en "directo" que hace todo más fresco a los ojos del espectador (Díez, 2005: 24).

Otra característica importante de Arminán como creador la señala López Izquierdo cuando destaca su habilidad al retratar el género humano: "Jaime de Armiñan hace la genealogía del español y presenta en su intimidad hombres y mujeres que se debaten entre la tradición y la modernidad" (Palacio, 2006: 48).

\subsubsection{Programación y producción en las comedias de Jaime Armiñán}

Respecto a la programación de estas primeras comedias, hay que tener en cuenta que la televisión franquista se caracterizó por su apuesta por contenidos de carácter popular, a mitad de camino entre el interés general, los intereses ideológicos y un marcado componente comercial de sus programas. Como indica José Ángel Cortés, "las televisiones de Estado se limitaban a ofrecer una serie de programas según un cierto sentido de la oportunidad, de la necesidad política, y del sentido común" (Cortés, 1999: 17). No existió, por tanto, ni el concepto de estrategia ni lo que posteriormente se ha conocido como lógica de programación. Sin embargo, podemos afirmar que las primeras comedias siguieron la tónica general existente en la programación de la época franquista en la cual, aunque no existía una estrategia comercial, sí se observa una clara adecuación a los ritmo de los telespectadores, así como una incipiente estrategia de fidelización, algo clave para el éxito de las series de televisión.

En concreto, tras analizar las parrillas publicadas durante los años 1959, 1960 y 1961 en la revista televisiva española más veterana Telediario (editada por la propia TVE desde el 31 de diciembre de 1957)5 , se encuentran varios patrones programáticos en la emisión de comedias, como por ejemplo, que estas series habitualmente se programan en horario de sobremesa y en jueves. Además, Telediario presenta la primera comedia televisiva de Armiñán, Galería de Maridos, como "un desenfadado sketch escrito por Jaime de Armiñán". Hay que destacar, por tanto, cómo esta serie se

5 "50 años de televisión en España". Ministerio de Educación, Cultura y Deporte. Disponible en: http://tv_mav.cnice.mec.es/siglo/50/ 
da a conocer al público como un sketch en el que la presencia de Armiñán se utiliza como reclamo para el público. Semanalmente iban desfilando por las pantallas diferentes tipos de maridos como en los títulos El aficionado al fútbol (Telediario, 1 de noviembre, 1959), El Aprensivo (Telediario, 8 de noviembre, 1959) o El Cocinilla (Telediario, 15 de noviembre, 1959).

Tabla 2. Programación de las primeras comedias de Jaime de Armiñán (1959-1961)

\begin{tabular}{|c|c|c|c|}
\hline Año & Título & $\begin{array}{c}\text { Hora de emisión } \\
\text { (Apróx. }\end{array}$ & Día de la semana \\
\hline 1959 & Galería de maridos & SOBREMESA (15:15) & Domingo \\
\hline 1959 & Galería de esposas & SOBREMESA (15:30) & Jueves \\
\hline 1960 & Cuando ellas veranean & NOCHE (22:00) & Jueves \\
\hline 1961 & Chicas en la ciudad & SOBREMESA (16:00) & Jueves \\
\hline 1961 & Mujeres solas & SOBREMESA (15:30) & Jueves \\
\hline
\end{tabular}

Fuente: Elaboración propia

Como estereotipos de mujeres que dan nombre a la serie Galería de esposas, la segunda exitosa comedia de Armiñán, encontramos a "La Hacendosa" en el día de su estreno el 10 de diciembre de 1960 (Telediario, 10 de diciembre, 1959), o "La que habla sola" (Telediario, 7 de enero, 1960). En el último episodio de la serie Galería de esposas, la revista Telediario la presenta así: "Un espacio que dice adiós. Margot Cottens. Antonio Ferrandis y Alicia Hermida darán vida a La Última Esposa que será como un resumen de todas cuantas se han retratado en la "galería". Jaime de Armiñán ha escrito este guión, con el convencimiento de que aún quedan esposas que caricaturizar con humor y ternura: tantas esposas como mujeres hay amantes de sus maridos y buenas amas de casa" (Telediario, 29 de septiembre, 1960).

Respecto a estas primeras comedias reseñadas de Armiñán, solamente Cuando ellas Veranean se ubica en un hueco que hoy llamaríamos de "prime time" nocturno en torno a las 22:00 horas. Según la revista Telediario en el anuncio del estreno el 4 de agoto de 1960, esta comedia se define como "un nuevo espacio de TVE, en el que el humor -el buen humor- es el protagonista junto con sus populares personajes de la vida nacional". Se resalta, por tanto, cómo las comedias de Armiñán no eran consideradas solamente comedias de autor, sino también una comedia de calidad y con buen humor.

Con la programación de Galería de esposas, Cuando ellas veranean, Chicas en la ciudad y Mujeres solas en los inicios de las primeras emisiones de TVE, el jueves en el horario de sobremesa se asienta como una franja dedicada a la comedia.

6 No existe un horario de emisión exacto diario. Los horarios de emisión oscilan varios minutos dependiendo de la semana. 
A medida que pasa la década de los 60 y ya entrados en los 70 su humor se torna menos amable, simpático y risueño con comedias más graves, secas y con un ingrediente de amargura como Las doce caras de Juan (1967), Historias de la frivolidad (1967), Las fábulas (1970), Las doce caras de Eva (1971) o su última producción para la televisión franquista Suspiros de España (1974).

Desde el punto de vista del contenido, Jaime de Armiñán fue uno de los primeros en utilizar la televisión como medio de difusión de ideas reformistas, puesto que el teatro ya no se considera el único gran acontecimiento social. Según Catalina Buezo, "los juicios de Armiñán saltan de la pantalla del televisor, y posteriormente de la gran pantalla, a la vida real y se convierten en modelos de interpretación de la vida social y política del momento" (Buezo, 2002). En sus trabajos se observa una clara orientación pedagógica desde el punto de vista del contenido, pero también una clara voluntad de entender el medio televisivo como una manera de narrar distinta al teatro televisivo en directo, propio de la época. Lejos de ser considera un transmisor de los valores del Régimen franquista a través de estas comedias, su obra se presente con una personalidad única, que le convierten en uno de los grandes autores, como guionista y director, de la televisión en nuestro país. Como señala Catalina Buezo (2002):

"La figura de Jaime de Armiñán actúa de puente entre la tradición y la modernidad, entre el desarrollismo y el tardofranquismo de la España de los sesenta y setenta y el proceso de transición democrática que culmina a principios de los ochenta con la victoria socialista. En esas décadas alcanza el éxito como guionista televisivo y posteriormente como cineasta gracias al desarrollo de una fórmula personal, realmente al margen de la "tercera vía", que lleva al máximo los límites del posibilismo dentro del mundo de la comedia, entendida a la manera aristotélica. Acusado de realizar un cine escapista por parte de un sector de la crítica española que le ha tratado con displicencia, es, en realidad, más que un continuador de la comedia de costumbres, un cineasta que cultiva un naturalismo fantástico que le sitúa fuera de las modas. Su presencia en festivales le ha otorgado la dimensión de autor que le corresponde" (Buezo, Catalina, 2002).

Ha sido, por tanto, Armiñán el indiscutible artífice de los seriales costumbristas en nuestra televisión, de un género estelar de la televisión, llámense, como en Estados Unidos o el Reino Unido, sitcom, comedias de situación, o simplemente telecomedias. Género cuya producción nacional abundó en aquellos años dorados de TVE.

Armiñán vivió y recorrió en estos seriales la historia de la tecnología televisiva: primero los realizó y emitió en directo en los primeros años ("hacíamos cosas inauditas, ni siquiera se ensayaba", comenta); los grabó después en vídeo, a partir del año 1960, cuando llega a España el primer magnetoscopio y cuando, como él recuerda ahora, "se grababa de un tirón y no por bloques, de manera que un error en el minuto 28 obligaba a repetir de nuevo toda la grabación", luego con el Electronic-Cam y en cine. Llegó a tener en antena dos series a la semana. El trabajo creativo que realiza el autor durante décadas es enorme ya que compatibiliza su ingente producción de series en televisión con la escritura de teatro y de guiones de cine. Para concluir este epígrafe detallaremos a continuación cómo era el proceso de producción de las comedias de los años 60 que se realizaban en directo: 
“Armiñán emplea uno o dos días en escribir el guión. Siempre escribe por la mañana o por la tarde. La idea del episodio suele partir de una noticia del periódico, de una lectura, de una conversación o de algo inmediato. Para que no le falten ideas, siempre lleva un cuaderno donde registra todo lo que tenga un interés dramático. Terminado y entregado el guión a los actores, dirige los ensayos y supervisa el ensayo general una hora antes de la retransmisión. Finalmente, durante la emisión, ayuda al realizador. Su función es asegurarse de que los actores siguen el texto. Incluso existe la posibilidad de grabar en vídeo, Armiñán prefiere hacer estos programas de 15 minutos en directo, ya que los actores se esfuerzan más y logran una mayor soltura y espontaneidad" (Díez, 2005: 27).

\section{Discusión}

En estas líneas se ha pretendido poner de manifiesto la importancia de los primeros años de emisión televisiva en España en la creación y consolidación de uno de los géneros televisivos con más popularidad en nuestro país, tanto a nivel de producción como de programación. Tras el recorrido por sus principales producciones, sobre todo las creadas por Jaime de Armiñán en los años 60, se han subrayado las características que consagraron a este género en nuestras parrillas y que se encuentran latentes también en la comedia televisiva actual. A continuación se exponen los datos novedosos que presenta este artículo:

1. Se ha puesto de manifiesto la relevancia de las variables de producción y programación en la configuración la industria de las primeras comedias televisivas. Sin restar importancia a otras variables como la escritura de guión, que irá en décadas posteriores imitando estándares de la industria estadounidense (Grandío y Diego, 2009), la producción de las primeras comedias representa el surgimiento del formato de telecomedia en España como la transición natural de las obras teatrales al formato televisivo, respectando su esencia claramente teatral en la estética y actuación de los actores. Por su parte, la programación de las primeras comedias de Armiñan demuestran una versatilidad de ubicación en la parrilla debido a su corta duración (desde la sobremesa, lo más habitual, al prime time), un tipo de estrategia de programación que, por otro lado, se ha perdido en el sistema televisivo actual, sistema que potencia las telecomedias de producción propia de estreno en horario ceñido al prime time, principalmente. El tiempo y el beneplácito de la audiencia han avalado el resultado final derivado de este tipo de producción y facilidad de inclusión en la parrilla propias de las primeras comedias televisivas. Actualmente sigue siendo uno de los formatos de ficción estrella de la televisión comercial española.

2. Como aspectos significativos en el nivel de producción de las primeras comedias, hay que destacar la corta duración de los scketches, su amplia influencia del teatro, así como el predominio del directo. Como ADN de la comedia televisiva, estas tres cuestiones originales de las primeras comedias en TV en España representan un valor añadido en los formatos de humor en la actualidad. Recordemos la grabación en directo del capítulo 200 de la serie 7 Vidas en el 2006 (Fórmula TV, 2006) precisamente por rescatar esa esencia de la comedia televisiva.

3. Respecto a la programación hay que destacar que, debido a su corta duración, las comedias eran un formato asiduo en la sobremesa de los primeros años de TVE, instaurando un consumo de la comedia televisiva que podríamos calificar como ágil 
y dinámico. La brevedad del formato, así como su programación en horarios de "relajamiento" como representa en aquella época la sobremesa, propicia que la audiencia vaya creando ciertos hábitos de consumo y quiera repetir esa experiencia audiovisual de entretenimiento como un ritual. Se instaura, por tanto, la fidelización televisiva con una comedia, derivado del acompañamiento de este formato televisivo a las rutinas diarias de la audiencia. Destaca esta afirmación en un contexto televisivo, como presenta la época de monopolio de TVE, en la que no existía una estrategia de programación televisiva comercial. Sin embargo, la programación de las primeras comedias de televisión demuestra un entendimiento, por parte de los programadores, del papel de la comedia dentro de una parrilla televisiva convencional y generalista, junto con un conocimiento del tipo de consumo que un formato de humor conlleva.

4. La existencia en los primeros años de programación de TVE de series que podemos denominar de "autor", y en el caso que nos ocupa, aparecen "comedias de autor" de la mano de nombres como el de Jaime de Armiñán. Se observa en estos primeros años la existencia de comedias con un sello específico y que precisamente ganan un valor promocional en la personalidad del autor, tal y como se refleja en la información de las revistas televisivas de la época revisadas para estudiar las comedias de Armiñán. Por el contrario, esta tendencia de los orígenes de la comedia hacia las series de autor parece haberse diluido con los años, no apareciendo casi ningún nombre propio que avale las creaciones de las comedias televisivas actuales, quedando la autoría creativa diluida en el propio proceso. En este sentido, sería bueno recobrar la autoría propia de los inicios de la comedia en España, para elevar este formato televisivo el nivel artístico que puede alcanzar, y no únicamente comercial. La versatilidad de profesiones como Armiñán que, proviniendo del teatro, triunfó en la televisión y el cine, debería ser un ejemplo a seguir por los profesionales de la televisión en la actualidad ya que demuestra que, lo realmente indispensable en esta profesión es saber contar historias que entretengan a la audiencia con un sello personal.

\section{Referencias}

BAGET HERMS, Josep María (1993): Historia de la televisión en España 1956-1975. Barcelona, Feed-Back.

BERCIANO, Rosa (1999): La comedia enlatada. De Lucille Ball a Los Simpson. Barcelona, Gedisa.

BUEZO, Catalina (2002): “Jaime de Armiñán y los medios de comunicación social como difusores de las ideas reformistas". Espéculo. Revista de estudios literarios. Universidad Complutense de Madrid, en http://www.ucm.es/info/especulo/numero20/arminan.html, [consultado 10/12/11].

CARRASCO, Ángel (2011): "Representación de la sociedad urbana actual en la telecomedia española contemporánea: costumbrismo e identidad social". Mediaciones Sociales, 8, I semestre 2011, pp. 71-96. 
CORTÉS, José Ángel (1999): La estrategia de la seducción: la programación en la neotelevisión. Pamplona: EUNSA.

CREEBER, Glen (2001): The television genre book. London, B.F.I.

DIEGO, Patricia (2010): La ficción en la pequeña pantalla. Cincuenta años de series en España. Pamplona: Eunsa.

DÍEZ, Emeterio (2005): Jaime de Armiñán. Antología de guiones. Madrid, Universidad Camilo José Cela.

DÍEZ, Emeterio (2010): Victor Ruiz Iriarte. Dramátios para televisión. Madrid, Fragua.

EL PAÍS, 10 de octubre, 2013. Disponible en: http://cultura.elpais.com/cultura/2013/10/10/actualidad/1381428758_542784.html

EL PAÍS, 4 de agosto, 1981. Disponible en: http://elpais.com/diario/1981/08/04/cultura/365724004_850215.html

FÓRMULA TV, 12 de marzo de 2006. Disponible en: http://www.formulatv.com/noticias/1945/7-vidas-celebra-sus-200-capitulos-con-un-episodio-en-directo/

GALÁN FAJARDO, Elena (2012): "La posguerra española en formato de telenovela" en GIL, Fátima y MATEOS-PÉREZ, Javier: Qué cosas vimos con Franco..., Madrid, Rialp, pp. 99-134).

GARCÍA DE CASTRO, Mario (2002): La ficción televisiva popular. Una evolución de las series de televisión en España. Barcelona, Gedisa.

GRANDÍO, María del Mar y DIEGO, Patricia (2009): "La influencia de la sitcom americana en la producción de comedias televisivas en España. El caso de Friends y 7 vidas". Ámbitos, 18, pp. 83-97.

MONTES, Francisco José (2006): "Historia de la televisión en España". Anuario Jurídico y Económico Escurialense, 39, pp. 637-696.

MONTES, Francisco José, "Historia de Televisión Española". Anuario Jurídico y Económico Escurialense, Vol. XXXIX, 2006, pp. 637-696.

PALACIO, Manuel (2006): Las cosas que hemos visto. 50 años y más de TVE. Madrid, RTVE Instituto.

PALACIO, Manuel (2001): Historia de la televisión en España. Barcelona, Gedisa.

PUEBLA, Belén (2012): "La comedia de situación en España. Características y evolución del formato" en A.A.V.V.: Ficcionando. Series de televisión a la española, pp. 15-37. Madrid, Fragua.

RÍOS CARRATALÁ, Juan Antonio (1997): Lo sainetesco en el cine español. Alicante, Publicaciones de la Universidad de Alicante.

RUEDA LAFFOND, José Carlos y CORONADO RUIZ, Carlota (2010): “La televisión franquista ante el espejo. Ejemplos sobre la ficcionalización audiovisual de la televisión en la España de los años sesenta y setenta". Razón y Palabra, 72. [http://eprints.ucm.es/10660/, consultado 10/12/11]. 
TELEDIARIO, 1 de noviembre, 1959. Ministerio de Educación, Cultura y Deporte. Disponible en: http://tv_mav.cnice.mec.es/siglo/50/

TELEDIARIO, 10 de diciembre, 1959. Ministerio de Educación, Cultura y Deporte. Disponible en: http:/tv_mav.cnice.mec.es/siglo/50/

TELEDIARIO, 15 de noviembre, 1959. Ministerio de Educación, Cultura y Deporte. Disponible en: http://tv_mav.cnice.mec.es/siglo/50/

TELEDIARIO, 29 de septiembre, 1960. Ministerio de Educación, Cultura y Deporte. Disponible en: http://tv_mav.cnice.mec.es/siglo/50/loaded_movies/programaciones/1960/1960_09.pdf

TELEDIARIO, 4 de agoto, 1960. Ministerio de Educación, Cultura y Deporte. Disponible en: http://tv_mav.cnice.mec.es/siglo/50/loaded_movies/programaciones/1960/1960_08.pdf

TELEDIARIO, 7 de enero, 1960. Ministerio de Educación, Cultura y Deporte. Disponible en: http://tv_mav.cnice.mec.es/siglo/50/loaded_movies/programaciones/1960/1960_01.pdf

TELEDIARIO, 8 de noviembre, 1959. Ministerio de Educación, Cultura y Deporte. Disponible en: http://tv_mav.cnice.mec.es/siglo/50/

VILLAGRASA, José María (2010): ¡Atrápalos como puedas!. La competencia televisiva: programación y géneros. Valencia, Tirant lo Blanch. 